\title{
Impact of age on CD4 recovery and viral suppression over time among adults living with HIV who initiated antiretroviral therapy in the African Cohort Study
}

Emmanuel Bahemana ${ }^{1,2^{*}}$, Allahna Esber ${ }^{2,3^{*}}$, Nicole Dear ${ }^{2,3}$, Kavitha Ganesan $^{2,3}$, Ajay Parikh $^{2,3}$, Domonique Reed ${ }^{2,3}$, Lucas Maganga ${ }^{4}$, Samoel Khamadi ${ }^{1,2}$, Mucho Mizinduko $^{5}$, Anange Lwilla', Dorothy Mkondoo 1,2, Gwamaka Mwaisanga 1,2, Nancy Somi 1,2, John Owouth 2,6, Jonah Maswai ${ }^{2,7}$, Francis Kiweewa ${ }^{8}$, Michael Iroezindu ${ }^{2,9}$, Julie A. Ake ${ }^{2}$, Trevor A. Crowell ${ }^{2,3}$, Victor G. Valcour ${ }^{10}$ and Christina S. Polyak ${ }^{2,3}$ on behalf of the AFRICOS Study Group

\begin{abstract}
Introduction: With increased use of antiretroviral therapy (ART), HIV mortality rates are declining and people living with HIV (PLWH) are surviving longer. We characterized CD4 recovery and viral suppression among adults aged $<50$ and $\geq 50$ years living with HIV who initiated ART in the African Cohort Study (AFRICOS).

Methods: Beginning in January 2013, PLWH at twelve clinics in Kenya, Uganda, Tanzania and Nigeria underwent medical history review, CD4 and viral load testing as part of the ongoing African Cohort Study (AFRICOS). ART-naïve PLWH who initiated ART within 30 days of enrollment and had at least one year of follow-up were included in these analyses. To compare ART response in participants $<50$ years and $\geq 50$ years old, changes in CD4 count and viral load suppression after ART initiation were examined at different time points using linear and binomial regression with generalized estimating equations. Variables for time since ART initiation and the interaction between age group and time on ART were included in the model to evaluate longitudinal changes in CD4 recovery and viral suppression by age.

Results: Between January 2013 and September 2019, 2918 PLHV were enrolled in the cohort. Of these, 443 were ART naïve and initiated on ART within 30 days of enrollment, with $90 \%(n=399)$ aged $<50$ years old at ART initiation. At ART initiation, participants aged 50 and older had a higher median CD4 count compared to participants younger than 50 years of age although it did not reach statistical significance $\left(306 \mathrm{cell} / \mathrm{s} / \mathrm{mm}^{3}, \mathrm{IQR}: 130-547 \mathrm{vs}\right.$. 277cells $/ \mathrm{mm}^{3}$, IQR: 132-437). In adjusted models examining CD4 recovery and viral suppression there were no significant differences by age group over time. By the end of follow-up viral suppression was high among both groups of adults ( $96 \%$ of adults $\geq 50$ years old and $92 \%$ of adults $<50$ years old).
\end{abstract}

\footnotetext{
*Correspondence: ebahemana@wrp-t.org; aesber@hivresearch.org

${ }^{1}$ HJF Medical Research International, Inc., Mbeya, Tanzania

2 U.S. Military HIV Research Program, Walter Reed Army Institute of Research, Silver Spring, MD, USA

Full list of author information is available at the end of the article
}

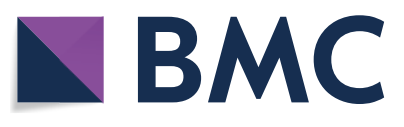

(c) The Author(s) 2020. This article is licensed under a Creative Commons Attribution 4.0 International License, which permits use, sharing, adaptation, distribution and reproduction in any medium or format, as long as you give appropriate credit to the original author(s) and the source, provide a link to the Creative Commons licence, and indicate if changes were made. The images or other third party material in this article are included in the article's Creative Commons licence, unless indicated otherwise in a credit line to the material. If material is not included in the article's Creative Commons licence and your intended use is not permitted by statutory regulation or exceeds the permitted use, you will need to obtain permission directly from the copyright holder. To view a copy of this licence, visit http://creativeco mmons.org/licenses/by/4.0/. The Creative Commons Public Domain Dedication waiver (http://creativecommons.org/publicdomain/ zero/1.0/) applies to the data made available in this article, unless otherwise stated in a credit line to the data. 
Conclusion: This study found no difference in long-term CD4 recovery or viral suppression by age at ART initiation. We found that particularly among younger adults participants had lower median CD4 counts at ART initiation, suggesting the importance of identifying and putting this population on treatment earlier in the disease course.

Keyword: HIV and aging, Sub-saharan Africa, Elders on antiretroviral drugs, HIV treatment outcomes

\section{Background}

In Africa, HIV/AIDS has largely been considered a disease of young people due to high rates of HIV infection in younger populations[1,2] and is the leading cause of death among young people in Africa and the second leading cause of death among young people worldwide [3]. However, with the advent of antiretroviral therapy (ART), persons living with HIV (PLWH) are living longer, the age distribution of the epidemic is shifting [4-8] and the life expectancy among PLWH and HIV-uninfected populations is relatively similar in recent years [9]. A study conducted in Kenya, Mozambique, Rwanda, and Tanzania found that the proportion of adults on ART aged 50 years and older increased from 10 to $16 \%$ between 2005 and 2010, primarily driven by aging of the existing patient population [10]. In 2016, approximately 2.4 million people aged 50 years and above were living with HIV in Sub-Saharan Africa [7]. This number is expected to triple by 2040 if treatment coverage remains widespread [3]. The major causes of morbidity and mortality among PLWH are no longer AIDS related, but are similar to people not living with HIV such as cancers, renal and liver diseases [11]. Many of the ongoing HIV interventions focus on younger age populations but it is important that HIV care and treatment programs consider the specific needs of the ageing population of PLWH as it continues to increase.

Ageing is a complex process affecting a wide variety of physiologic functions, including the development and maintenance of the peripheral immune system [12]. Most published data on immunologic responses to ART concern younger patients with very little published in older populations newly initiated on ART [13-15]. Evidence suggests that immune responses to HIV and ART may be different in older populations due to declines in thymic function leading to decreased thymic outputs and poor immunologic response to infections [16, 17]. Several studies of adults living with HIV and on ART suggest that differential immune responses are associated with thymus involution $[14,18,19]$.

Data regarding the immunologic response to ART in older PLWH have been inconsistent. A study conducted in four African countries found that the 12-month average CD4 response for adults 50 years and older initiating ART was 20.6 cells $/ \mathrm{mm}^{3}$ lower than for adults aged 25-39 years [20]. In contrast, several studies conducted in the United States did not find significant age-based differences in immune response after ART initiation. A clinic-based study in the United States that enrolled 906 ART naïve patients between February 1989 and January 2006 did not find significant differences in CD4 recovery after ART initiation by age when adjusting for CD4 count at the time of ART initiation [21,22]. Similarly, an analysis of two large observational clinical cohorts in the US failed to observe significant differences in mean CD4 recovery after ART initiation between adults younger than 50 years and those 50 years and older [21,23].

Conflicting findings have also been reported regarding viral load responses to ART initiation among adults. The majority of findings come from studies conducted in Europe and the US and report similar rates of viral suppression among adults aged $<50$ years and those $\geq 50$ years old $[15,24-26]$. However, findings from other studies have revealed that older ART initiators presented with lower viral suppression rates compared to younger PLHIV ART initiators [11, 27] While several studies have examined immunologic and virologic response in HIV-infected older adults, few studies have focused on the long-term impact of age at ART initiation on CD4 recovery and viral suppression in African settings. We examined changes in $\mathrm{CD} 4$ recovery and viral suppression after first ART initiation, stratified by age, in a unique longitudinal cohort across four African countries.

\section{Methods \\ Study design and participants}

This analysis is nested within the African Cohort Study (AFRICOS), which was established in 2013 and has been described previously [28]. In brief, AFRICOS is an ongoing prospective cohort study enrolling PLWH at twelve clinical sites in Kenya, Tanzania, Uganda, and Nigeria. PLWH were eligible for AFRICOS if they were $\geq 18$ years old, receiving HIV care at the enrolling PEPFAR clinic and consented to data and specimen collection. Individuals who were pregnant were not eligible for enrollment. The study was approved by the institutional review boards of the Walter Reed Army Institute of Research, the University of California San Francisco, the Makerere University School of Public Health, Kenya Medical Research Institute, the Tanzania National Institute of 
Medical Research, and the Nigerian Ministry of Defense. All participants provided written informed consent.

\section{Data collection and definitions}

Demographic and clinical variables including sex, age, education level, comorbidities, nadir CD4 count, adherence to ART medication, type of ART regimen at ART initiation and clinical care site were collected upon enrollment. CD4 count and viral load tests were performed every 6 months. Viral suppression was defined as a viral load $<1000$ copies $/ \mathrm{mL}$. To account for possible confounding effects, we included three noncommunicable diseases (NCDs) in our analyses: dysglycemia (fasting glucose $>99$ or any glucose $>199$ or on glucose medications), elevated blood pressure (systolic BP $>139$ or diastolic $\mathrm{BP}>89$ or on hypertension medications), hypercholesterolemia (cholesterol $>199$ or on cholesterol medications). Self-reported adherence to ART medication was assessed at each study visit. Participants were classified as adherent if they reported not missing any doses in the 30 days prior to the visit. We classified ART regimen into two categories based on the most common ART prescribed across the sites: on efavirenz/lamivudine/tenofovir, or on any other drug combination. We used a continuous CD4 measurement and viral suppression defined as viral load $<1000$ copies/mL to determine treatment outcomes.

To ensure comparability of data across the sites, standard operating procedures for vital signs were followed and laboratory measures were performed at laboratories that were accredited by the College of American Pathologists or had successfully completed external quality assurance.

Data were entered and verified into an electronic data capture and management software (Clinplus platform;DZS Software Solutions, Bound Brock, NJ).

\section{Statistical analyses}

ART-naïve PLWH who were enrolled as of September 1, 2019, initiated on ART within 30 days of enrollment and had at least one year of follow up time were included in these analyses. Participants were categorized into two groups by age at ART initiation: $<50$ and $\geq 50$ years based on the WHO/CDC definition for older age [29]. The association between age group and population-averaged CD4 count and virologic suppression was evaluated using linear and binomial regression with generalized estimating equations. An independent working correlation was included to account for repeated observations in the same individual. Variables for time since ART initiation and the interaction between age group and time were included in the model to evaluate the longitudinal changes in mean $\mathrm{CD} 4$ and virologic suppression by age stratum. Confounders were selected based on a $10 \%$ change in coefficients and variables classified as confounders for one outcome were locked into the model for subsequent outcomes. We restricted these analyses to the first 42 months of follow up to ensure adequate sample size at each time point.

In order to further assess response in CD4 we conducted a few additional analyses. First, we used logistic regression to estimate the odds of a $50 \mathrm{cell} / \mathrm{mm}^{3}$ increase in CD4 six months after ART initiation and a 100 cell/ $\mathrm{mm}^{3}$ increase in CD4 12 months after ART initiation comparing the two age groups. Last, we used binomial regression with generalized estimating equations to estimate the odds of reaching a CD4 $\geq 500$ cells $/ \mathrm{mm}^{3}$ during the follow up period after ART initiation. All analyses were performed in Stata 15.0 (StataCorp, College Station, Texas).

\section{Results}

\section{Cohort characteristics at enrollment}

Between January 2013 and September 2019, 2918 PLHV were enrolled in the cohort. Of these, 443 were ART naïve and initiated on ART within 30 days of enrollment. The Kenyan sites constituted the plurality of participants (35.2\%), followed by Tanzania (27.8\%), Uganda (21.2\%), and Nigeria (15.8\%; Table 1$)$. There was a significant variation by age, with $90 \%(\mathrm{n}=399)$ of participants aged $<50$ years old at ART initiation. The median age of participants $<50$ was 35.3 years (Interquartile range (IQR) 29.9-40.9 years) and 55.2 years (IQR 52.459.1 years) for those $\geq 50$ years $(p<0.001)$. Females constituted $58.5 \%$ of all participants with $59.9 \%$ and $45.5 \%$ among $<50$ and $\geq 50$ years old respectively $(p=0.07)$. There was a statistically significant difference in the number of comorbidities recorded at enrollment among participants aged $<50$ and $\geq 50$ years, with fewer comorbidities among participants aged $<50$ years $(p<0.001)$. The majority (96\%) of participants initiated ART on an efavirenz based regimen while 13 participants initiated ART on a nevirapine based regimen and three participants on a protease inhibitor. No participants initiated ART on an integrase inhibitor.

\section{CD4 recovery}

At ART initiation, participants aged 50 and older had a higher median CD4 count compared to participants younger than 50 years of age $\left(306 \mathrm{cells} / \mathrm{mm}^{3}\right.$, IQR:130-547 vs. 277 cells/mm³ ${ }^{3}$ IQR: 132-437). After six months of follow up, median CD4 count increased in both age groups $(\geq 50$ : 380 , IQR: $183-702 ;<50$ : 397, IQR: 226-583). In both unadjusted and adjusted models, there were no significant time and age interactions, suggesting no differences in mean CD4 
Table 1 Demographic and clinical characteristics of study participants at ART initiation

\begin{tabular}{|c|c|c|c|c|}
\hline & All participants $n=443$ & $<50$ years $n=399$ & $\geq 50$ yearsn $=44$ & $p$ value \\
\hline Study site & & & & 0.18 \\
\hline Kayunga, Uganda & $94(21.2 \%)$ & $87(21.8 \%)$ & $7(15.9 \%)$ & \\
\hline South Rift Valley, Kenya & $105(23.7 \%)$ & $90(22.6 \%)$ & $15(34.1 \%)$ & \\
\hline Kisumu West, Kenya & $51(11.5 \%)$ & $47(11.8 \%)$ & $4(9.1 \%)$ & \\
\hline Mbeya, Tanzania & $123(27.8 \%)$ & $108(27.1 \%)$ & $15(34.1 \%)$ & \\
\hline Abuja \& Lagos Nigeria & $70(15.8 \%)$ & $67(16.8 \%)$ & $3(6.8 \%)$ & \\
\hline $\begin{array}{l}\text { Age at ART initiation (years), median } \\
\text { (IQR) }\end{array}$ & $36.4(30.5,43.2)$ & $35.3(29.9,40.9)$ & $55.25(52.4,59.1)$ & $<0.001$ \\
\hline Gender & & & & 0.07 \\
\hline Male & $184(41.5 \%)$ & $160(40.1 \%)$ & $24(54.5 \%)$ & \\
\hline Female & $259(58.5 \%)$ & $239(59.9 \%)$ & $20(45.5 \%)$ & \\
\hline Education & & & & $<0.01$ \\
\hline None or some primary & $118(26.6 \%)$ & $97(24.3 \%)$ & $21(47.7 \%)$ & \\
\hline Primary or some secondary & $197(44.5 \%)$ & $186(46.6 \%)$ & $11(25.0 \%)$ & \\
\hline Secondary and above & $128(28.9 \%)$ & $116(29.1 \%)$ & $12(27.3 \%)$ & \\
\hline Elevated blood pressure & & & & $<0.001$ \\
\hline No & $401(90.5 \%)$ & $371(93.0 \%)$ & $30(68.2 \%)$ & \\
\hline Yes & $42(9.5 \%)$ & $28(7.0 \%)$ & $14(31.8 \%)$ & \\
\hline Dysglycemia & & & & 0.63 \\
\hline No & 367 (93.9\%) & $332(94.1 \%)$ & 35 (92.1\%) & \\
\hline Yes & $24(6.1 \%)$ & $21(5.9 \%)$ & $3(17.9 \%)$ & \\
\hline Hypercholesterolemia & & & & 0.10 \\
\hline No & $358(89.7 \%)$ & $326(90.6 \%)$ & $32(82.1 \%)$ & \\
\hline Yes & $41(10.3 \%)$ & $31(9.4 \%)$ & $7(17.9 \%)$ & \\
\hline CD4 nadir, median (IQR) & $259(122.5,389)$ & $257(119.5,384.5)$ & $326.5(141,545.5)$ & 0.22 \\
\hline ART regimen at initiation & & & & 0.62 \\
\hline TDF/EFV/3TC & $427(96.4 \%)$ & $384(96.2 \%)$ & $43(97.7 \%)$ & \\
\hline Other & $16(3.6 \%)$ & $15(3.8 \%)$ & $1(2.3 \%)$ & \\
\hline
\end{tabular}

IQR Interquartile Range, TDF tenofovir, EFV efavirenz, 3TC lamivudine, ART antiretroviral therapy

recovery by age group over time (Table 2). There were no significant differences by age group in odds of a CD4 increase of 50 cells $/ \mathrm{mm}^{3}$ at 6 months after ART initiation, 100 cells $/ \mathrm{mm}^{3}$ at 12 months post-ART initiation, or achieving a CD4 count greater than 500 cells/ $\mathrm{mm}^{3}$ during the course of follow up (Fig. 1).

\section{Viral suppression}

In both the unadjusted and adjusted model, there were no significant differences in viral suppression at any time point between the two age groups (Table 3). By the end of the follow-up period, at 42 months post ART initiation, viral suppression was high among both groups of adults, with $96 \%$ of adults $\geq 50$ years old virally suppressed and $91 \%$ of adults $<50$ years old virally suppressed ( $p=0.43$; Fig. 2 ).

\section{Discussion}

We found that time since ART initiation rather than age was the primary driver of CD4 recovery and viral suppression among new ART initiators. Importantly, among adults of all ages, there was a large sustained increase in mean CD4 count and in the proportion of participants who were virally suppressed.

Though some other studies have documented that older PLWH initiating ART mount poorer CD4 cell responses than younger patients, our findings do not support these arguments but rather add to the growing body of evidence that immune recovery does not differ among older adult ART initiators [11, 18, 22, 26, 27]. A cohort study conducted in Italy among adult PLWH admitted between 1997 and 2003, found that older ART initiators can achieve the same immunologic recovery as younger ART initiators [10]. Another clinic-based cohort study 
Table 2 Unadjusted and Adjusted Change in CD4 for participants $<\mathbf{5 0}$ and $\geq \mathbf{5 0}$ years by time since ART initiation

\begin{tabular}{|c|c|c|c|c|}
\hline & \multicolumn{2}{|c|}{ Unadjusted change in CD4 } & \multicolumn{2}{|c|}{ Adjusted change in $\mathrm{CD}^{\mathrm{a}}$} \\
\hline & Average CD4 & $95 \% \mathrm{Cl}$ & Average CD4 & $95 \% \mathrm{Cl}$ \\
\hline Constant & 306 & $283-330$ & 282 & $218-345$ \\
\hline Age $\geq 50$ & 52 & $-38-142$ & 37 & $-58-132$ \\
\hline \multicolumn{5}{|l|}{ Time } \\
\hline 6 months & 128 & $108-148$ & 146 & $124-166$ \\
\hline 12 months & 156 & $135-178$ & 174 & 150-199 \\
\hline 18 months & 176 & 153-199 & 192 & $166-217$ \\
\hline 24 months & 188 & $163-214$ & 203 & $174-231$ \\
\hline 30 months & 217 & $185-248$ & 230 & $197-263$ \\
\hline 36 months & 195 & $162-228$ & 213 & $179-247$ \\
\hline 42 months & 199 & $161-237$ & 289 & $225-353$ \\
\hline \multicolumn{5}{|l|}{ Age ${ }^{*}$ visit interaction } \\
\hline Age $\geq 50^{*} 6$ months & -20 & $-66-26$ & -3 & $-62-55$ \\
\hline Age $\geq 50 * 12$ months & -48 & $-101-4$ & -29 & $-96-38$ \\
\hline Age $\geq 50^{*} 18$ months & -35 & $-100-29$ & -22 & $-95-51$ \\
\hline Age $\geq 50 * 24$ months & 47 & $-41-135$ & 66 & $-28-162$ \\
\hline Age $\geq 50 * 30$ months & -38 & $-129-54$ & -11 & $-106-84$ \\
\hline Age $\geq 50^{*} 36$ months & -71 & $-182-40$ & -52 & $-159-55$ \\
\hline Age $\geq 50^{*} 42$ months & -147 & $-263-31$ & -130 & $-377-116$ \\
\hline
\end{tabular}

a Adjusted for study site, education, gender, dysglycemia and hypercholesterolemia

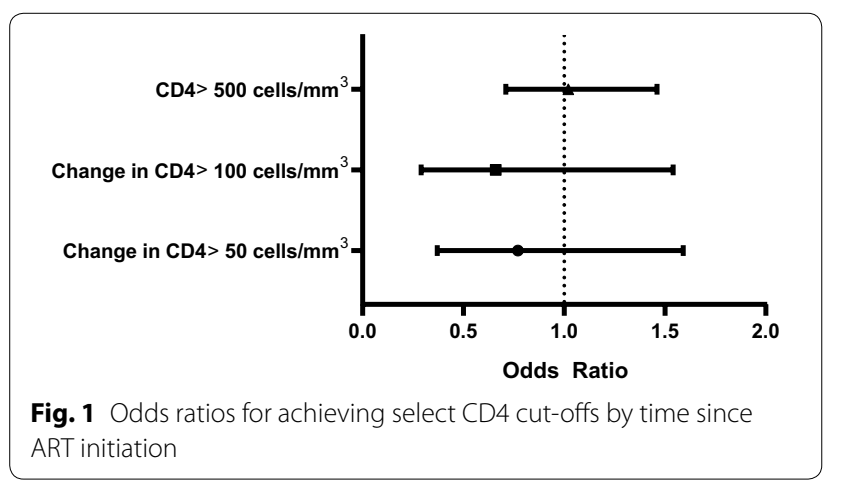

conducted in the United States which followed 906 ARTnaïve patients for a median duration of 46 months, found similar null findings after adjusting for CD4 count at the time of ART initiation [21, 22]. Other studies conducted in the US and Europe have failed to observe significant differences in $\mathrm{CD} 4$ response among adults aged $<50$ years and those 50 years and older, after initiation of ART[21, 23]. This study extends similar findings in four countries in sub-Saharan Africa. In contrast, other studies have found differences in CD4 among older and younger individuals although these studies may differ from our findings due to the older population studied and differing ART initiation guidelines in practice at the time of the study $[10,30]$.
Table 3 Unadjusted and Adjusted Odds Ratio for Viral suppression between participants $<50$ and $\geq \mathbf{5 0}$ years by time since ART initiation

\begin{tabular}{|c|c|c|c|c|}
\hline & \multicolumn{2}{|c|}{ Unadjusted OR } & \multicolumn{2}{|c|}{ Adjusted OR ${ }^{a}$} \\
\hline & OR & $95 \% \mathrm{Cl}$ & aOR & $95 \% \mathrm{Cl}$ \\
\hline \multicolumn{5}{|l|}{ Age } \\
\hline$<50$ & Ref & & - & \\
\hline$\geq 50$ & 1.21 & $0.73-2.00$ & 1.23 & $0.71-2.13$ \\
\hline \multicolumn{5}{|l|}{ Time } \\
\hline ART initiation & Ref & & - & \\
\hline 6 months & 4.29 & $3.56-5.17$ & 4.38 & $3.53-5.43$ \\
\hline 12 months & 4.29 & $3.56-5.16$ & 4.48 & $3.65-5.50$ \\
\hline 18 months & 4.26 & $3.54-5.13$ & 4.26 & $3.43-5.30$ \\
\hline 24 months & 4.16 & $3.45-5.02$ & 4.30 & $3.49-5.29$ \\
\hline 30 months & 4.33 & $3.59-5.23$ & 4.50 & $3.64-5.56$ \\
\hline 36 months & 4.34 & $3.60-5.22$ & 4.39 & $3.56-5.40$ \\
\hline 42 months & 4.50 & $3.73-5.43$ & 4.74 & $3.82-5.89$ \\
\hline \multicolumn{5}{|l|}{ Age ${ }^{*}$ visit interaction } \\
\hline Age $\geq 50 * 6$ months & 0.82 & $0.49-1.39$ & 0.78 & $0.42-1.47$ \\
\hline Age $\geq 50^{*} 12$ months & 0.88 & $0.53-1.45$ & 0.84 & $0.49-1.44$ \\
\hline Age $\geq 50^{*} 18$ months & 0.83 & $0.50-1.37$ & 0.86 & $0.49-1.53$ \\
\hline Age $\geq 50 * 24$ months & 0.92 & $0.55-1.52$ & 0.90 & $0.52-1.57$ \\
\hline Age $\geq 50 * 30$ months & 0.85 & $0.51-1.41$ & 0.80 & $0.45-1.44$ \\
\hline Age $\geq 50 * 36$ months & 0.86 & $0.50-1.47$ & 0.84 & $0.46-1.51$ \\
\hline Age $\geq 50 * 42$ months & 0.81 & $0.46-1.42$ & 0.86 & $0.50-1.49$ \\
\hline
\end{tabular}

a Adjusted for study site, education, gender, dysglycemia and hypercholesterolemia 


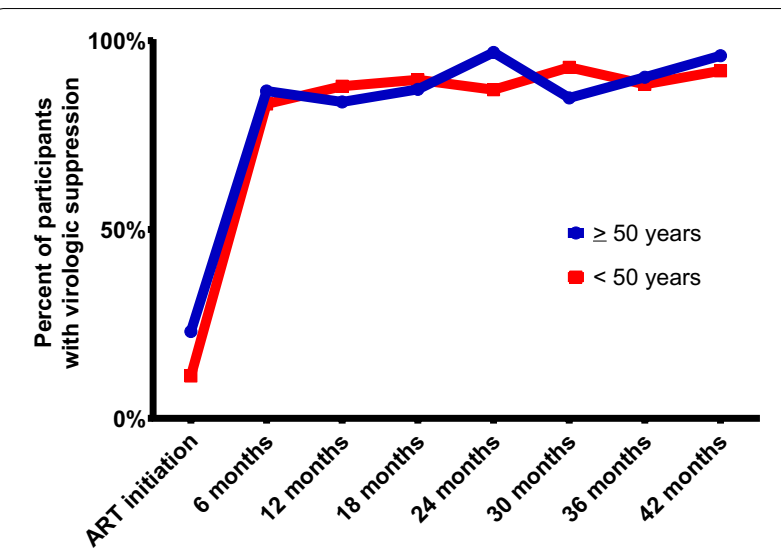

Fig. 2 Proportion of participants virally suppressed over time, by age group

Our study found out that younger participants presented with lower mean CD4 counts at ART initiation compared to adults. This may be attributed to delayed testing due in part to a number of reasons including inadequate HIV and sexual education as well as lack of HIV services and stigma [3,31]. Results from surveys conducted between 2011 and 2016 in sub-Saharan Africa showed that only $10 \%$ of adolescent boys and $15 \%$ of adolescent girls in sub-Saharan Africa had tested for HIV in the last 12 month [32]. However, although it was not statistically significant, we observed a trend toward faster immune response among younger participants compared to older participants in the acute phase of ART initiation. This is consistent with findings from the Multicenter AIDS Cohort Study (MACS) that revealed at acute phase of ART therapy, immune responses to ART were faster in younger groups compared to older groups, possibly due to bigger thymic size and active functionality, which become compromised with age $[16,17]$. That younger PLWH have a faster initial immunologic response is likely outweighed in the long run by behavioral factors and poor ART adherence reported among young ART initiators [33].

We also characterized changes in viral suppression among ART naïve adults in this cohort. We found that both age groups responded well virologically to ART and sustained high levels of viral suppression for the duration of the follow-up period, over three years after initiating ART. Many studies conducted in Europe and the US found similar rates of viral suppression among adults aged $<50$ years and those $\geq 50$ years $[15,21,24-26]$. An analysis of a clinic-based cohort in France to evaluate the effect of age on ART efficacy and tolerance in 639 patients with HIV infection (99 aged $<50$ years, and 540 aged $\geq 50$ years) found similar virologic response among age groups after six months of follow-up [21]. In contrast, some studies have shown that older ART initiators reach viral suppression at a faster rate and maintain suppression for longer [22, 34-37]. A large cohort conducted in nine sites in Argentina, Brazil, Chile, Haiti, Honduras, Mexico and Peru with more than 26,000 participants found better viral suppression among adults 50 years and older as compared to those less than 50 years [38], which is likely due to differences in adherence rather than physiological reasons. Findings from an analysis of the USbased cohorts found that HIV-infected ART-naïve adults initiated on ART achieved virologic suppression faster than younger PLWH [13, 22, 27]. Increased viral suppression among adults 50 years and older may support the idea that older PLWH tend to avoid risk behaviors and have better ART adherence [24, 27, 39].

Strengths of this study include the long follow up time of 42 months for participants after initiation of ART. We also were able to capture information on other NCDs that may influence immune response, particularly among older participants. We acknowledge several limitations of this study. Many AFRICOS participants were already initiated on ART at enrollment limiting the sample size for these analyses, with a smaller proportion of adults $\geq 50$ years of age compared to adults younger than 50 years (1:9), potentially allowing for outliers in the older age category to exhibit greater influence on mean CD4. The smaller sample size of participants $\geq 50$ also limited our power to detect significant differences in mean CD4 between the two age groups. However, in the sensitivity analyses examining dichotomous CD4 the findings remained unchanged. Participants enrolled in AFRICOS receive an optimized care package and therefore may not be generalizable to the general careseeking population. ART adherence was self-reported rather than measured by pill counts, which is prone to recall and social desirability bias. However, given the high percentage of participants virally suppressed after visit one we feel that participants were largely reliable in reporting good ART adherence. Large windows around study visits could potentially create imprecision around immune responses measured at different time points; however, as estimates of CD4 and viral load remained relatively constant at subsequent visits we feel these limitations had minimal impact. Lastly, participants are only seen every six months, so we were unable to assess changes in CD4 and viral load within a timeframe less than 6 months after ART initiation as other studies have $[40,41]$. 


\section{Conclusion}

This study found no difference in long-term CD4 recovery or viral suppression by age at ART initiation. Despite the fact that the difference was not statistically significant, we found that participants, particularly younger adults, had lower CD4 counts at ART initiation, suggesting the importance of identifying and putting this population on treatment earlier in the disease course.

\section{Abbreviations}

ART: Antiretroviral Therapy; HIV: Human Immunodeficiency Virus; WHO: World Health Organization; AIDS: Acquired Immune deficiency Syndrome; UNAIDS: United States Agency for International Development; AFRICOS: African cohort study; PEPFAR: President's Emergency Plan for AIDS Relief; RNA: Ribonucleic Acid; IRB: Institutional Review Board; PLWH: People Living With HIV.
\end{abstract}

\section{Acknowledgements}

We thank the study participants, study staff, hospital leadership at Kayunga District Hospital, Kericho District Hospital, AC Litein Mission Hospital, Kapkatet District Hospital, Tenwek Mission Hospital, Kapsabet District Hospital, Nandi Hills District Hospital, Kisumu West District Hospital, Mbeya Zonal Referral Hospital, Defence Headquarters Medical Center, and 68th Nigerian Army Reference Hospital.

We would also like to thank the AFRICOS Study Group: MHRP Clinical Research Directorate: J. Hern, E. Duff, MHRP Data Coordination and Analysis Center: A. Reynolds, D. Bartolanzo, K. Song, M. Milazzo, L. Francisco, MHRP Clinical Operations Office: S. Schech, A. Golway, T. Mebrahtu. MHRP Department of International HIV Prevention Treatment: E. Lee, K. Bohince, T. Hamm. MHRP International Laboratory Program: K. Lombardi, M. Imbach, L. Eller. WRAIR HIV Diagnostics Reference Lab: S. Peel, J. Malia. Ludwig Maximilian University of Munich, Munich, Germany: A. Kroidl, I. Kroidl, C. Geldmacher. Kayunga District Hospital, Kayunga, Uganda: C. Kafeero, A. Nambuya, J. Tegamanyi, H. Birungi, O Mugagga, G. Nassali, P. Wangiri, M. Nantabo, P. Nambulondo, B. Atwijuka, A. Asiimwe, C.T. Nabanoba, M. Semwogerere, R. Mwesigwa, S. Jjuuko, R. Namagembe, E. Bagyendagye, A. Tindikahwa, I. Rwomushana, F. Ssentongo, H. Kibuuka, M. Millard. Kericho District Hospital, Kericho, Kenya: J. Kapkiai, S. Wangare, R. Mangesoi, P. Chepkwony, L. Bor, E. Maera, A. Kasembeli. AIC Litein Hospital, Litein, Kericho, Kenya: J. Rotich, C. Kipkoech, W. Chepkemoi, A. Rono. Kapkatet District Hospital, Kabkatet, Kericho, Kenya: Zeddy Kesi, Janet Ngeno, Edwin Langat, Keneddy Labosso, Ken Langat, Robert Kirui. Tenwek Mission Hospital, Bomet, Bomet, Kenya: L. Rotich, M. Mabwai, E. Chelangat, J. Agutu, C. Tonui. Nandi Hills District Hospital, Nandi Hills, Kenya: E. Changwony, M. Bii, E.Chumba, J. Korir. Kapsabet District Hospital, Kapsabet, Nandi, Kenya: J. Sugut, D. Gitonga, R. Ngetich, S. Kiprotich. Kenya Medical Research Institute, Kisumu, Kenya: W. Rehema, C. Ogari, I. Ouma, O. Adimo, S. Ogai, C. Okwaro, E. Maranga, J. Ochola, K. Obambo, V. Sing'oei, L. Otieno, O. Nyapiedho, N. Sande, E. Odemba, F. Wanjiru Walter Reed Program-Tanzania, Mbeya, Tanzania: E. Chiweka, P. Kiliba, M. Mwaipopo, J. Muhumuza. Mbeya Zonal Referral Hospital, Mbeya, Tanzania: N. Mkingule, O. Mwasulama, A. Sanagare, P. Kishimbo. National Institute of Medical Research, Mbeya Medical Research Centre, Mbeya, Tanzania: G. David, F. Mbwayu, J. Mwamwaja, J. Likiliwike, J. Muhumuza, R. Mcharo, N. Mkingule, O. Mwasulama, B. Mtafya, C. Lueer, A. Kisinda, T. Mbena, H. Mfumbulwa, L. Mwandumbya, P. Edwin, W. Olomi. Walter Reed ProgramNigeria, Abuja, Nigeria: Y. Adamu, A. Akintunde, A. B. Tiamiyu, K. Afoke, S. Mohammed. 68 Nigerian Army Reference Hospital, Yaba, Lagos, Nigeria: N.E. Harrison, U.C. Agbaim, O.A. Adegbite, Z. Parker, G.A. Adelakun, F.O. Oni, R.O Ndbuisi, J. Elemere. Defense Headquarters Medical Center, Abuja, Nigeria: N. Azuakola, T.T. Williams, M. Ayogu, O. Enas, O. Enameguono, A.F. Odo, I.C. Ukaegbu, O.Ugwuezumba . Defense Reference Lab, Abuja, Nigeria: S.O. Odeyemi, N C Okeke, L Umeji, A. Rose, H. Daniel, H. Nwando, E.I. Nicholas, T lyanda, C. Okolo, V. Y. Mene, B, Dogonyaro, O. Olabulo, O. Akinseli, F. Onukun, G. Knopp

\section{Prior presentation}

This work was presented, in part, at ASTMH 2017 in Baltimore, MD, 5-9 November 2017.

\section{Disclaimer}

The views expressed are those of the authors and should not be construed to represent the positions of the U.S. Army or the Department of Defense or the Department of Health and Human Services. The investigators have adhered to the policies for protection of human subjects as prescribed in AR-70.

\section{Authors' contributions}

$E B, A E, C P$ and $M M$ conceived of the presented research idea. EB, LM, SK, $\mathrm{AL}, \mathrm{DM}, \mathrm{GM}, \mathrm{FK}, \mathrm{JO}, \mathrm{JM}, \mathrm{MI}, \mathrm{KG}, \mathrm{AP}$ and NS carried out the data collection, laboratory activities and reviewed the collected data for quality and reliability. $A E, N D$, and $D R$ designed the model and the computational framework and analysed the data. EB, AE, TC, ND and CP contributed to the interpretation of the results. EB took the lead in writing the manuscript. W, CP and JA were in charge of overall direction and planning. All authors provided critical feedback and helped shape the research, analysis and manuscript. All authors read and approved the final manuscript.

\section{Funding}

This work was supported by a cooperative agreement (W81XWH-11-2-0174) between the Henry M. Jackson Foundation for the Advancement of Military Medicine, Inc., and the U.S. Department of Defense (DOD). This research has been supported by the President's Emergency Plan for AIDS Relief (PEPFAR) through the U.S. Department of Defense.

\section{Availability of data and materials}

The Henry M. Jackson Foundation for the Advancement of Military Medicine (HJF) and the Water Reed Army Institute of Research (WRAIR) are committed to safeguarding the privacy of research participants. Distribution of data will require compliance with all applicable regulatory and ethical processes, including establishment and approval of an appropriate data-sharing agreement. To request a minimal data set, please contact the data coordinating and analysis center (DCAC) at PubRequest@hivresearch.org and indicate the RV329 study along with the name of the manuscript.

\section{Ethics approval and consent to participate}

The study was approved by the institutional review boards of the Walter Reed Army Institute of Research, the University of California San Francisco, the Makerere University School of Public Health, Kenya Medical Research Institute, the Tanzania National Institute of Medical Research, and the Nigerian Ministry of Defense. All participants provided written informed consent.

\section{Consent for publication}

Not applicable.

\section{Competing interests}

The authors declare that they have no competing interests.

\section{Author details}

${ }^{1}$ HJF Medical Research International, Inc., Mbeya, Tanzania. ${ }^{2}$ U.S. Military HIV Research Program, Walter Reed Army Institute of Research, Silver Spring, MD, USA. ${ }^{3}$ Henry M. Jackson Foundation for the Advancement of Military Medicine, Bethesda, MD, USA. ${ }^{4}$ National Institute for Medical Research-Mbeya Medical Research Center, Mbeya, Tanzania. ${ }^{5}$ Muhimbili University of Health and Allied Science-Dar-Es-Salaam, Dar-Es-Salaam, Tanzania. ${ }^{6}$ HJF Medical Research International, Kisumu, Kenya. ${ }^{7}$ HJF Medical Research International, Kericho, Kenya. ${ }^{8}$ Makerere University Walter Reed Project, Kampala, Uganda. ${ }^{9}$ HJF Medical Research International, Abuja, Nigeria. ${ }^{10}$ Memory and Aging Center, Department of Neurology, University of California, San Francisco, CA, USA.

Received: 11 August 2020 Accepted: 3 November 2020

Published online: 12 November 2020

\section{References}

1. United Nations Programme on HIV/AIDS (UNAIDS). UNAIDS report on the global AIDS epidemic. 2010

2. United Nations Programme on HIV/AIDS (UNAIDS). UNAIDS data 2019. 2020. 
3. UNAIDS. UNAIDS report shows that 19 million of the 35 million people living with HIV today do not know that they have the virus | UNAIDS. UNAIDS: Press Release. Geneva; 2014.

4. Mahy M, Autenrieth CS, Stanecki K, Wynd S. Increasing trends in HIV prevalence among people aged 50 years and older: Evidence from estimates and survey data. AIDS. 2014. https://doi.org/10.1097/QAD.00000 00000000479

5. Hontelez JAC, de Vlas SJ, Baltussen R, Newell M-L, Bakker R, Tanser F, et al. The impact of antiretroviral treatment on the age composition of the HIV epidemic in sub-Saharan Africa. AIDS. 2012;26(Suppl 1):S19-30.

6. Negin J, Cumming RG. HIV infection in older adults in sub-Saharan Africa: extrapolating prevalence from existing data. Bull World Health Organ. 2010:88(11):847-53.

7. Autenrieth CS, Beck EJ, Stelzle D, Mallouris C, Mahy M, Ghys P. Global and regional trends of people living with HIV aged 50 and over: Estimates and projections for 2000-2020. PLoS ONE. 2018. https://doi.org/10.1371/journ al.pone. 0207005 .

8. Costagliola D. Demographics of HIV and aging. Curr Opin HIV AIDS. 2014;9(4):294-301.

9. Palella FJ, Delaney KM, Moorman AC, Loveless MO, Fuhrer J, Satten GA, HIV Outpatient Study Investigators, et al. Declining morbidity and mortality among patients with advanced human immunodeficiency virus infection. N Engl J Med. 1998;338(13):853-60.

10. Eduardo E, Lamb MR, Kandula S, Howard A, Mugisha V, Kimanga D, et al. Characteristics and outcomes among older HIV-positive adults enrolled in HIV programs in four sub-Saharan African countries. PLOS ONE. 2014a;9(7):e103864.

11. Manfredi R, Chiodo F. A case-control study of virological and immunological effects of highly active antiretroviral therapy in HIV-infected patients with advanced age. AIDS. 2000;14(10):1475-7.

12. Miller RA. The aging immune system: primer and prospectus. Science. 1996. https://doi.org/10.1126/science.273.5271.70.

13. Grabar S, Le Moing V, Goujard C, Leport C, Kazatchkine MD, Costagliola D, et al. Clinical outcome of patients with HIV-1 infection according to immunologic and virologic response after 6 months of highly active antiretroviral therapy. Ann Intern Med. 2000. https://doi. org/10.7326/0003-4819-133-6-200009190-00007.

14. Kaufmann GR, Zaunders JJ, Cunningham P, Kelleher AD, Grey P, Smith $D$, et al. Rapid restoration of CD4 T cell subsets in subjects receiving antiretroviral therapy during primary HIV-1 infection. AIDS. 2000. https:// doi.org/10.1097/00002030-200012010-00003.

15. Yamashita TE, Phair JP, Muñoz A, Margolick JB, Detels R, O'Brien SJ, et al. Immunologic and virologic response to highly active antiretroviral therapy in the Multicenter AIDS Cohort Study. AIDS. 2001. https://doi. org/10.1097/00002030-200104130-00009.

16. Compston JE. Bone marrow and bone: a functional unit. J Endocrinol. 2002. https://doi.org/10.1677/joe.0.1730387.

17. Lewis J, Payne H, Walker AS, Otwombe K, Gibb DM, Babiker AG, et al. Thymic output and CD4 T-cell reconstitution in HIV-infected children on early and interrupted antiretroviral treatment: evidence from the children with HIV early antiretroviral therapy trial. Front Immunol. 2017:8:1162.

18. Douek DC, McFarland RD, Keiser PH, Gage EA, Massey JM, Haynes BF, et al. Changes in thymic function with age and during the treatment of HIV infection. Nature. 1998;396(6712):690-5.

19. Mpondo BCT. HIV Infection in the elderly: arising challenges. J Aging Res. 2016. https://doi.org/10.1155/2016/2404857.

20. Eduardo E, Lamb MR, Kandula S, Howard A, Mugisha V, Kimanga D, et al. Characteristics and outcomes among older HIV-positive adults enrolled in HIV programs in four sub-Saharan African countries. PLOS ONE. 2014b. https://doi.org/10.1371/journal.pone.0103864.

21. Cuzin L, Delpierre C, Gerard S, Massip P, Marchou B. Immunologic and clinical responses to highly active antiretroviral therapy in patients with HIV infection aged $>50$ years. Clin Infect Dis. 2007;45(5):654-7.

22. Greenbaum AH, Wilson LE, Keruly JC, Moore RD, Gebo KA. Effect of age and HAART regimen on clinical response in an urban cohort of HIVinfected individuals. AIDS. 2008:22(17):2331-9.

23. Patterson KB, Napravnik S, Eron J, Keruly J, Moore R. Effects of age and sex on immunological and virological responses to initial highly active antiretroviral therapy. HIV Med. 2007. https://doi.org/10.111 1/j.1468-1293.2007.00485.x.

24. Manfredi R. HIV infection and advanced age emerging epidemiological, clinical, and management issues. Ageing Res Rev. 2004;3(1):31-54.

25. Knobel H, Guelar A, Valldecillo G, Carmona A, González A, López-Colomés $J \mathrm{~L}$, et al. Response to highly active antiretroviral therapy in HIV-infected patients aged 60 years or older after 24 months follow-up. AIDS. 2001. https://doi.org/10.1097/00002030-200108170-00025.

26. Viard JP, Mocroft A, Chiesi A, Kirk O, Røge B, Panos G, et al. Influence of age on CD4 cell recovery in human immunodeficiency virus-infected patients receiving highly active antiretroviral therapy: evidence from the EuroSIDA study. J Infect Dis. 2001;183(8):1290-4.

27. Goodkin K, Shapshak P, Asthana D, Zheng W, Concha M, Wilkie FL, et al. Older age and plasma viral load in HIV-1 infection. AIDS. 2004;18(Suppl 1):S87-98.

28. Ake JA, Polyak CS, Crowell TA, Kiweewa F, Semwogerere M, Maganga L, et al. Noninfectious comorbidity in the African Cohort Study. Clin Infect Dis. 2019:69(4):639-47.

29. Centers for Disease Control and Prevention. AIDS Among Persons Aged greater than or equal to 50 Years -- United States, 1991-1996. MMWR. 1998:47(02):21-7.

30. De ALR, Pallikkuth S, George V, Rinaldi S, Pahwa R, Arheart KL, et al. Reevaluation of immune activation in the era of CART and an aging HIV-infected population. JCl Insight. 2017;2(20):1-14.

31. UNICEF. Adolescent deaths from AIDS tripled since 2000-UNICEF. New York: UNICEF; 2015.

32. United Nations Programme on HIV/AIDS (UNAIDS). HIV and AIDS in adolescents. 2020.

33. Vinikoor MJ, Joseph J, Mwale J, Marx MA, Goma FM, Mulenga LB, et al. Age at antiretroviral therapy initiation predicts immune recovery, death, and loss to follow-up among HIV-infected adults in urban Zambia. AIDS Res Hum Retroviruses. 2014. https://doi.org/10.1089/aid.2014.0046.

34. Le Moing V, Chêne G, Carrieri MP, Alioum A, Brun-Vézinet F, Piroth L, et al. Predictors of virological rebound in HIV-1-infected patients initiating a protease inhibitor-containing regimen. AIDS. 2002. https://doi. org/10.1097/00002030-200201040-00004

35. Bosch RJ, Bennett K, Collier AC, Zackin R, Benson CA. Pretreatment factors associated with 3-year (144-week) virologic and immunologic responses to potent antiretroviral therapy. J Acquir Immune Defic Syndr. 2007. https ://doi.org/10.1097/QAl.0b013e31802c7e20.

36. Nogueras MM, Navarro G, Antón E, Sala M, Cervantes M, Amengual MJ, et al. Epidemiological and clinical features, response to HAART, and survival in HIV-infected patients diagnosed at the age of 50 or more. BMC Infect Dis. 2006. https://doi.org/10.1186/1471-2334-6-159.

37. Paredes R, Mocroft A, Kirk O, Lazzarin A, Barton SE, Van Lunzen J, et al. Predictors of virological success and ensuing failure in HIV-positive patients starting highly active antiretroviral therapy in Europe: Results from the EuroSIDA Study. Arch Intern Med. 2000. https://doi.org/10.1001/archi nte.160.8.1123.

38. Carriquiry G, Giganti MJ, Castilho JL, Jayathilake K, Cahn P, Grinsztejn B, et al. Virologic failure and mortality in older ART initiators in a multisite Latin American and Caribbean Cohort. J Int AIDS Soc. 2018;21(3):e25088.

39. Meffert SM, Neylan TC, McCulloch CE, Maganga L, Adamu Y, Kiweewa F, et al. East African HIV care: depression and HIV outcomes. Glob Ment Health. 2019. https://doi.org/10.1017/gmh.2019.6.

40. Wellons MF, Sanders L, Edwards LJ, Bartlett JA, Heald AE, Schmader KE. HIV infection: treatment outcomes in older and younger adults. J Am Geriatr Soc. 2002. https://doi.org/10.1046/j.1532-5415.2002.50152.x.

41. Goetz MB, Boscardin WJ, Wiley D, Alkasspooles S. Decreased recovery of CD4 lymphocytes in older HIV-infected patients beginning highly active antiretroviral therapy. AIDS. 2001. https://doi.org/10.1097/00002030200108170-00017.

\section{Publisher's Note}

Springer Nature remains neutral with regard to jurisdictional claims in published maps and institutional affiliations. 